\title{
Quantitative assessment of myocardial perfusion by magnetic resonance imaging in the isolated porcine heart
}

\author{
Andreas Schuster ${ }^{1 *}$, Amedeo Chiribiri ${ }^{1}$, Masaki Ishida', Matthias Paul ${ }^{1}$, Shazia Hussain', \\ Niloufar Zarinabad Nooralipour ${ }^{1}$, Geraint Morton ${ }^{1}$, Roy Jogiya ${ }^{1}$, Divaka Perera ${ }^{1}$, Tobias Schaeffter ${ }^{1}$, Sven Plein ${ }^{2}$, \\ Eike Nagel ${ }^{1}$
}

From 2011 SCMR/Euro CMR Joint Scientific Sessions

Nice, France. 3-6 February 2011

\section{Objective}

To validate quantitative myocardial perfusion CMR against known myocardial blood flow rates in the isolated perfused porcine heart.

\section{Background}

Perfusion imaging visualizes early changes within the ischaemic cascade and has been shown to accurately detect significant coronary artery stenoses. First pass myocardial perfusion CMR yields high spatial resolution and permits quantification of myocardial blood flow. However, perfusion-CMR has only been validated in a small number of previous studies and using relatively early perfusion methods. An isolated blood-perfused MR compatible porcine heart model which can be imaged by identical equipment used for humans has been recently proposed. The model permits full control of regional myocardial blood flow, thus providing a valuable tool for the validation of quantitative perfusion assessment.

\section{Methods}

9 perfusion experiments were performed in male white cross landrace pigs $(54 \pm 6 \mathrm{~kg})$. Hearts were harvested under terminal anaesthesia and transported to the laboratory under cold cardioplegic arrest. After reperfusion the coronary flow rate was set by an external pump to accommodate stable sinus rhythm. Myocardial blood

'King's College London BHF Centre of Excellence, Division of Imaging Sciences, NIHR Biomedical Research Centre at Guy's and St. Thomas' NHS Trust Foundation, Wellcome Trust EPSRC Medical Engineering Centre; The Rayne Institute, St. Thomas' Hospital, London, UK

Full list of author information is available at the end of the article flow of $0.8 \mathrm{ml} / \mathrm{min} / \mathrm{g}$ was considered normal reference flow of $100 \%$.

Hearts were positioned in a clinical 1.5 Tesla MR Scanner (Philips Achieva) and myocardial perfusion CMR was performed with a k-t SENSE accelerated highresolution balanced Turbo Field Echo pulse sequence yielding a spatial resolution of $1.7 \times 1.9 \times 10 \mathrm{~mm}$. Perfusion-CMR was performed using a dual bolus scheme $(5 \mathrm{ml}$ of neat $(7 \mathrm{mmol} / \mathrm{l})$ and $5 \mathrm{ml}$ of dilute $(0.7 \mathrm{mmol} / \mathrm{l})$ gadobutrolum, Gadovist, Schering, Berlin, Germany) and quantified using Fermi function constrained deconvolution. Values were expressed as Mean \pm SD per slice (6 region of interests) and compared with the known coronary flow rate.

\section{Results}

Hearts remained stable during isolated coronary perfusion and thus experiments were successfully conducted. Mean myocardial blood flow of the external pump was set to $96 \pm 33 \%$. There was good correlation with mean myocardial perfusion as assessed by CMR $(95 \pm 38 \%)$ using simple linear regression analysis $(\mathrm{r}=0.95$, mean difference $0.35 \%$, limits of agreement $+24.43 \%$ and $-23.74 \%)$. Figure 1 shows the quantitative result of each experiment in regard to the externally set blood flow.

\section{Conclusion}

Quantitative assessment of myocardial perfusion using CMR correlates well with known myocardial blood flow in an isolated porcine heart model. Further studies using fluorescently labelled microspheres as the goldstandard are required to confirm this finding. 


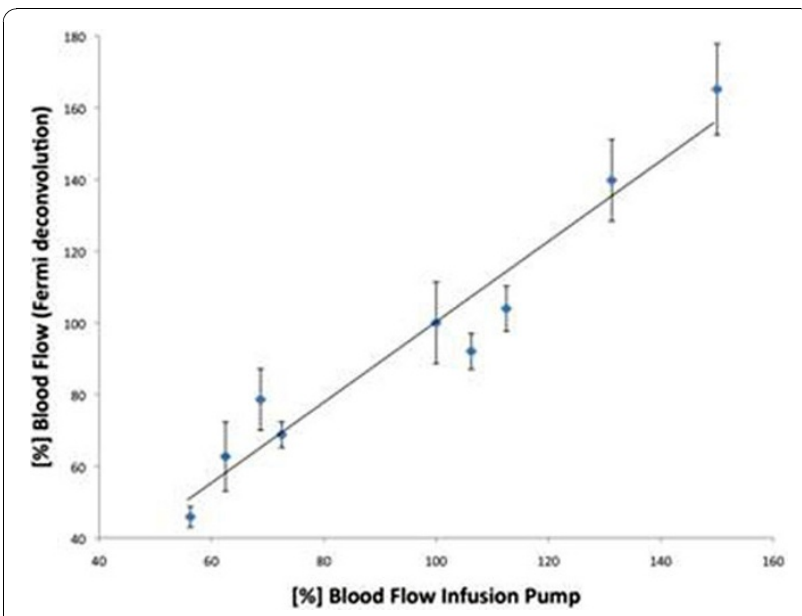

Figure 1 Relation between [\%] Myocardial Blood Flow given by the infusion pump and [\%] Blood Flow derived from magnetic resonance perfusion imaging (Fermi deconvolution).

\section{Author details}

'King's College London BHF Centre of Excellence, Division of Imaging Sciences, NIHR Biomedical Research Centre at Guy's and St. Thomas' NHS Trust Foundation, Wellcome Trust EPSRC Medical Engineering Centre; The Rayne Institute, St. Thomas' Hospital, London, UK. 'King's College London BHF Centre of Excellence, Division of Imaging Sciences, The Rayne Institute, St. Thomas' Hospital \& University of Leeds, Multidisciplinary Cardiovascular Research Centre, G-floor Jubilee Wing, Leeds General Infirmary, Leeds LS1 3EX, London \& Leeds, UK.

Published: 2 February 2011

doi:10.1186/1532-429X-13-S1-P55

Cite this article as: Schuster et al:: Quantitative assessment of myocardial perfusion by magnetic resonance imaging in the isolated porcine heart. Journal of Cardiovascular Magnetic Resonance 2011 13(Suppl 1):P55.

\section{Submit your next manuscript to BioMed Central} and take full advantage of:

- Convenient online submission

- Thorough peer review

- No space constraints or color figure charges

- Immediate publication on acceptance

- Inclusion in PubMed, CAS, Scopus and Google Scholar

- Research which is freely available for redistribution

Submit your manuscript at www.biomedcentral.com/submit 